ORIGINAL ARTICLE

\title{
Goldsmith Workers (GSWs): A Skilled Job \& Status of Illness
}

\author{
*M Rahman 1 , TT Sajani ${ }^{2}$ \\ ${ }^{1}$ Dr. MD. Mahfuzar Rahman, Professor and Head, Department of Community Medicine \\ Anwer Khan Modern Medical College. \\ ${ }^{2}$ Dr. Tabassum Tahmin Sajani, Assistant Professor, Department of Community Medicine \\ Anwer Khan Modern Medical College \\ *Corresponding Author
}

Date of submission: 02 February $2015 \quad$ Date of acceptance: 07 April 2015

\begin{abstract}
Background: This study was conducted among the goldsmith workers of different goldsmith's workshops located Islampur of Dhaka city to find out respiratory illness among them.

Methodology: It was a descriptive cross sectional study. By purposive sampling a total of 120 goldsmith workers were interviewed about respiratory problems using questionnaire and checklist.

Result: The study revealed out of 120 respondents $5 \%$ were illiterate, $40 \%$ had education upto Primary level and 55\% respondents had education at secondary level and above. Around 31.7\% and 30.8\% respondents had monthly income 7100-9000 and 9100-11000 taka respectively. Most of them had length of service 6-20 years (72.5\%) and $25.8 \%$ had length of service $>20$ years. The study showed $37.5 \%$ had been suffering from respiratory illness and among them $75.6 \%$ were suffering from cough for 3months or more in a year, $66.7 \%$ suffering from cough with phlegm, $18.9 \%$ Blood mixed phlegm, $71.1 \%$ running nose/ sneezing and $33.3 \%$ were suffering from breathlessness. 96.7\% respondents had knowledge on use of personal protective equipments (PPE). Around 58.3\% respondents were smoker and their mean duration of smoking habit was 15.59 ( 7.36) years. PEFR was significantly low $(\mathrm{p}<0.001)$ both in sitting and standing position among the respondents suffering from respiratory problems. Mean PEFR on sitting position was $426.22 \mathrm{~L} / \mathrm{min}$ and 430.33 $\mathrm{L} / \mathrm{min}$ in standing position in respondents with respiratory problems. Conclusion: This indicates $37.5 \%$ respondents are suffering from chronic obstructive pulmonary disease and necessitates preventive and therapeutic measures to minimize sufferings of goldsmith workers.
\end{abstract}

Key Words: Respiratory illness, Goldsmith workers.

\section{Introduction}

From the ancient period of human life, peoples were engaged in making ornaments with gold of various designs to make themselves beautiful. With advancement of civilization people also changed their life style and have inclined to increased use of varieties design of ornament. A group of people are engaged for making different type of ornaments with gold, known as goldsmith worker. ${ }^{1}$

Work related disabilities represent a major public health problem. Despite modest reduction in the number of occupational injuries and illness, the number of lost work days related to these injuries or illness continue to rise. ${ }^{1}$

The people who work in goldsmith workshops develop various types of health problems similar to

AKMMC J 2015; 6(2): 05-10 the problems of blacksmith. Goldsmith workers are directly exposed to coal dust, fumes of wax and acid. Coal dust, fumes of wax and acid may cause pulmonary and non pulmonary problems. Pulmonary problems are sneezing, rhinitis; cough with or without sputum, breathlessness, chest pain etc. Non pulmonary effects are musculoskeletal pain, mechanical injury, conjunctivitis, foreign body in the eyes, dermatitis, vertigo, headache, hyperacidity etc. Toxic chemicals may cause dermatitis, irritation of respiratory tract, irritation of GI tract and impairment of nervous system. ${ }^{2}$

This study was performed to find out respiratory problems among the goldsmiths of selected workshops in Dhaka city to reveal important and 
significant information regarding their respiratory problems, so that some specific measures may be taken to prevent or minimize such problems among the goldsmith workers in future.

\section{Methodology}

A descriptive cross sectional study was done among the goldsmith workers in different goldsmith workshops located Islampur of Dhaka city from March 2009 to June 2009. The study area was selected purposively as there are many goldsmith workshops located in that area. Data were collected from 120 respondents through face to face interviews with the help of questionnaire ad checklist. Respiratory tests like PEFR (Peak Expiratory Flow Rate) in sitting and standing position by PEFR meter, Chest expansibility, breadth sound were also examined. After data collection data were consolidated, processed and edited by using computers to reduce errors. Statistical methods were used for analysis and interpretation of data.

\section{Results}

Among 120 respondents $40.8 \%$ belonged to age group of 3645 years and $37.5 \%$ age group 2635 years. The mean $( \pm \mathrm{SD})$ age was $36.14( \pm 8.01)$ years. Only 5\%) respondents were illiterate and educational level of others were $40 \%$ primary, $40.8 \%$ secondary and $14.2 \%$ higher secondary level. Most of the respondents had monthly income $7,1009,000(31.7 \%)$, followed by $9,10011,000$ (30.8\%), 5,100 7,000 (20.8\%), >11,000 (10.2\%) and $<5,000(6.7 \%) \quad$ Taka/month. Mean $( \pm S D)$ monthly income was Taka 8,608.33 $( \pm 2,208.83)$. (Table-1)

Around half of the total respodents $52.5 \%$ were working as gorith and $25 \%$ as chila. Length of service as goldsmith was $<5$ years in case of only $1.7 \%$ respondents, for others, it varied in between 6 and $>20$ years, $20 \%$ for 610 years, $25 \%$ for 1115 years, $27.5 \%$ for 1620 years and $25.8 \%$ for $>20$ years. The mean $( \pm \mathrm{SD})$ length of service was $17.26( \pm 7.11)$ years. Maximum number of respondents work for up to 8 hours per day $(66.7 \%)$ and $20 \%$ for 910 hours. The mean $( \pm$ SD) working hours was $8.73( \pm 1.14)$. (Table-2)
Out of 120 respondents, respiratory problem was present in $45(37.5 \%)$ and absent in $75(62.5 \%)$ workers.(Figure-1)

Among the 45 respondents with respiratory illness, all $45(100 \%)$ were suffering from cough, 34 (75.6\%) from cough for 3 months or more in a year, $30(66.7 \%)$ when coughing usually brings phelegm, in $4(18.9 \%)$ phlegm were blood mixed, $32(71.1 \%)$ running nose and/or sneezing and 15 (33.3\%) experienced breathlessness.(Table-3)

Maximum number of respondents were aware on the use of Personal Protective Equipment (PPE) at workplace (96.7\%).(Table-4) But only $52.5 \%$ uses goggles and $46.7 \%$ use masks. (Figure-2)

$58.3 \%$ respondents were smokers. In order of frequency, out of these 70 smokers, 25 (35.7\%) smoked > 15 cigarettes/sticks per day, $20(28.6 \%)$ smoked 1115 sticks/day, 14 (20\%) smoked 610 sticks/day and $11(15.7 \%)$ smoked $<5$ sticks/day. The mean $( \pm$ SD) sticks/day smoked was 14.89 $( \pm 7.38)$.Duration of smoking habit of these 70 smokers. Around $40 \%$ has smoking habit of $>16$ year. The mean $( \pm S D)$ duration of smoking habit was $15.59( \pm 7.36)$ years. (Table-5)

The mean $( \pm \mathrm{SD})$ chest expandability status was $3.10( \pm 0.41) \mathrm{cm}$ among respondents. $70.8 \%$ had chest expandability of $<3 \mathrm{~cm}, 21.7 \%$ had 3.13 .5 $\mathrm{cm}$ and $7.5 \%$ had $3.64 .0 \mathrm{~cm}$.(Table-6)

PEFR was significantly low $(\mathrm{p}<0.001)$, both in sitting and standing position, among respondents suffering from respiratory problems. Mean $( \pm$ SD) PEFR in sitting position was $426.22( \pm 65.45)$ $\mathrm{L} / \mathrm{min}$ in respondents suffering from respiratory problems and $472.00( \pm 61.01) \mathrm{L} / \mathrm{min}$ in respondents not suffering from any respiratory problem. In standing position PEFR was 430.33 $( \pm 64.49)$ and $476.13( \pm 61.65) \mathrm{L} / \mathrm{min}$, respectively. (Table-7) 
AKMMC J $2015: 6(2)$

Table-1: Distribution of baseline characteristics of respondents $\mathrm{n}=120$

\begin{tabular}{ll}
\hline Characteristics & Frequency \\
\hline Age & $11(9.2)$ \\
$16-25$ & $45(37.5)$ \\
$26-35$ & $49(40.8)$ \\
$36-45$ & $15(12.5)$ \\
$>45$ & \\
Level of education & \\
Illiterate & $6(5.0)$ \\
Primary & $48(40.0)$ \\
Secondary & $49(40.8)$ \\
Higher secondary & $17(14.2)$ \\
Monthly income & \\
5,000 & $8(6.7)$ \\
$\leq 5100-7000$ & $25(20.8)$ \\
$7100-9000$ & $38(31.7)$ \\
$9100-11000$ & $37(30.8)$ \\
$>11000$ & $12(10.2)$ \\
\end{tabular}

Percentage in parenthesis

Table-2: Distribution of respondents by working hour and length of service $n=120$

\begin{tabular}{ll}
\hline Characteristics & Frequency \\
\hline Working section & $63(52.5)$ \\
Gorith & $30(25.0)$ \\
Chila & $13(10.8)$ \\
Chetting & $13(10.8)$ \\
Polishing & $1(0.8)$ \\
Manager & \\
Working hour per day & $80(66.7)$ \\
$<8 \mathrm{hr}$ & $36(20.0)$ \\
$9-10 \mathrm{hr}$ & $3(2.5)$ \\
$11-12 \mathrm{hr}$ & $1(0.8)$ \\
$13-14 \mathrm{hr}$ & \\
Length of service & $2(1.7)$ \\
$\leq 5 \mathrm{yrs}$ & $24(20.0)$ \\
$6-10 \mathrm{yrs}$ & $30(25.0)$ \\
$11-15 \mathrm{yrs}$ & $33(27.5)$ \\
$16-20 \mathrm{yrs}$ & $31(25.8$ \\
$>20 \mathrm{yrs}$ & Percentage in parenthesis
\end{tabular}

M Rahman, TT Sajani

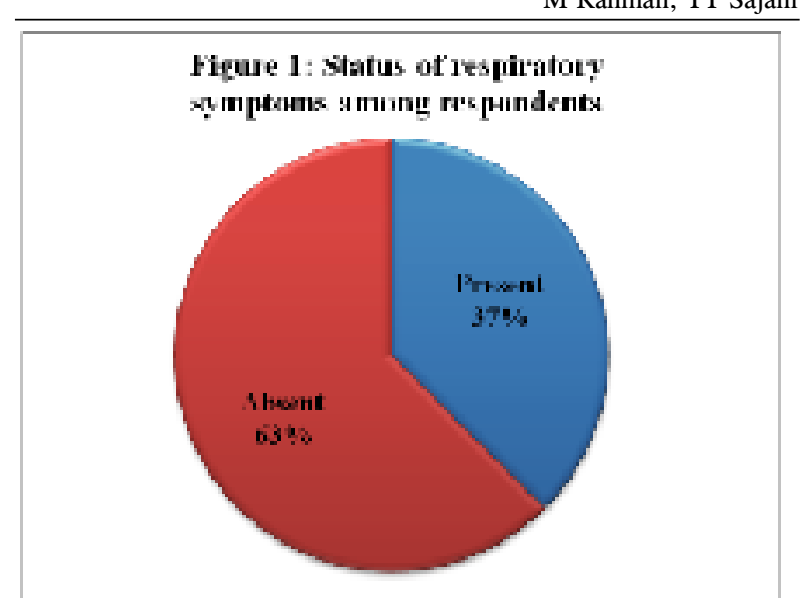

Table-3: Respiratory symptoms of the respondents $(\mathrm{n}=45)$

\begin{tabular}{lcc}
\hline Cough & 45 & 100.00 \\
Suffer from cough for 3 months & & \\
or more in a year & 34 & 75.6 \\
Coughing, usually brings phlegm & 30 & 66.7 \\
Blood mixed phlegm & 4 & 18.9 \\
Running nose and/or sneezing & 32 & 71.1 \\
Breathlessness & 15 & 33.3 \\
\hline
\end{tabular}

Table-4: Knowledge of the respondents on PPE use $(\mathrm{n}=120)$

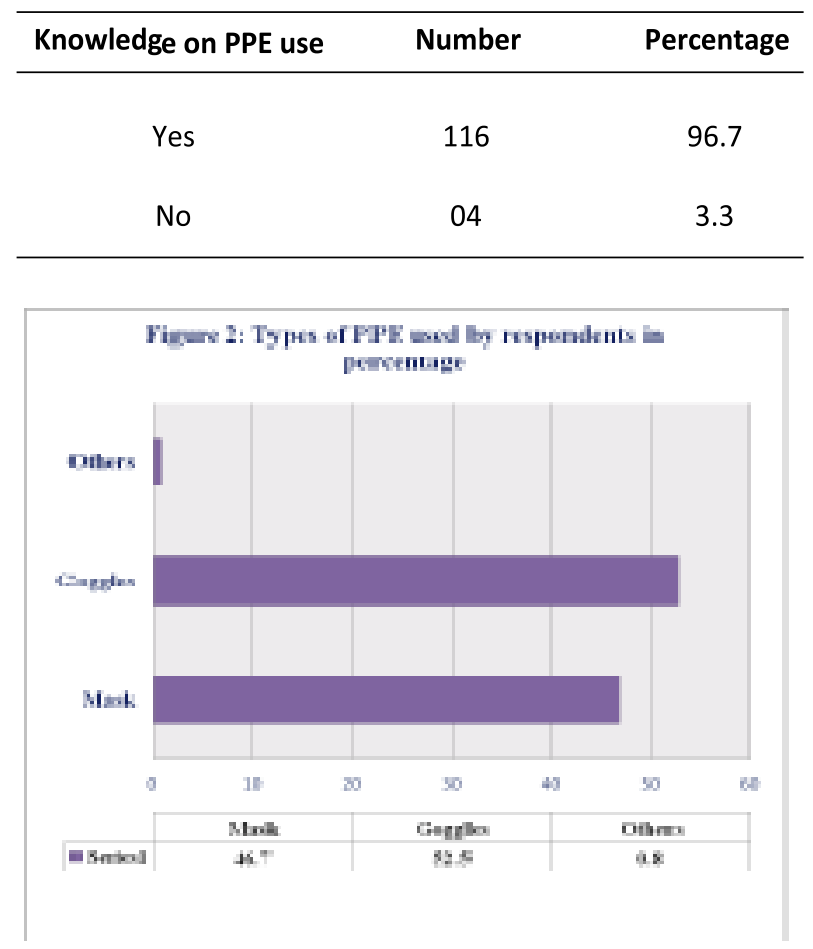


Goldsmith Workers (GSWs): A Skilled Job \& Status of Illness

Table-5: Smoking habits of the respondents

\begin{tabular}{lcc}
\hline Parameters & Number & Percentage \\
\hline $\begin{array}{l}\text { Smoking habit }(\mathrm{n}=120) \\
\text { Yes }\end{array}$ & 70 & 58.3 \\
No & 50 & 41.7 \\
Number of cigarettes smoked & & \\
per day (n=70) & & \\
$\leq 5$ & 11 & 15.7 \\
$6-10$ & 14 & 20.0 \\
$11-15$ & 20 & 28.6 \\
$>15$ & 25 & 357 \\
Mean \pm SD & & $14.89 \pm 7.38$ \\
\hline Duration (years) of & & \\
smoking habit $(\mathrm{n}=70)$ & & 8.6 \\
5 & 6 & 24.3 \\
$6-10$ & 17 & 27.1 \\
$11-15$ & 19 & 20.0 \\
1620 & 14 & 20.0 \\
$>20$ & $14.59 \pm 7.36$ \\
Mean \pm SD & & \\
\hline
\end{tabular}

Table-6: Chest expandability status of the respondents

\begin{tabular}{lrr}
\hline Chest & Number & Percentage \\
expandability (cm) & 85 & 70.8 \\
\hline$\leq 3$ & & \\
& 26 & \\
$3.1-3.5$ & & \\
& & \\
$3.6-4.0$ & 9 & \\
& & \\
Mean \pm SD & & \\
\hline
\end{tabular}

Table-7: Effect of respiratory symptoms on PEFR

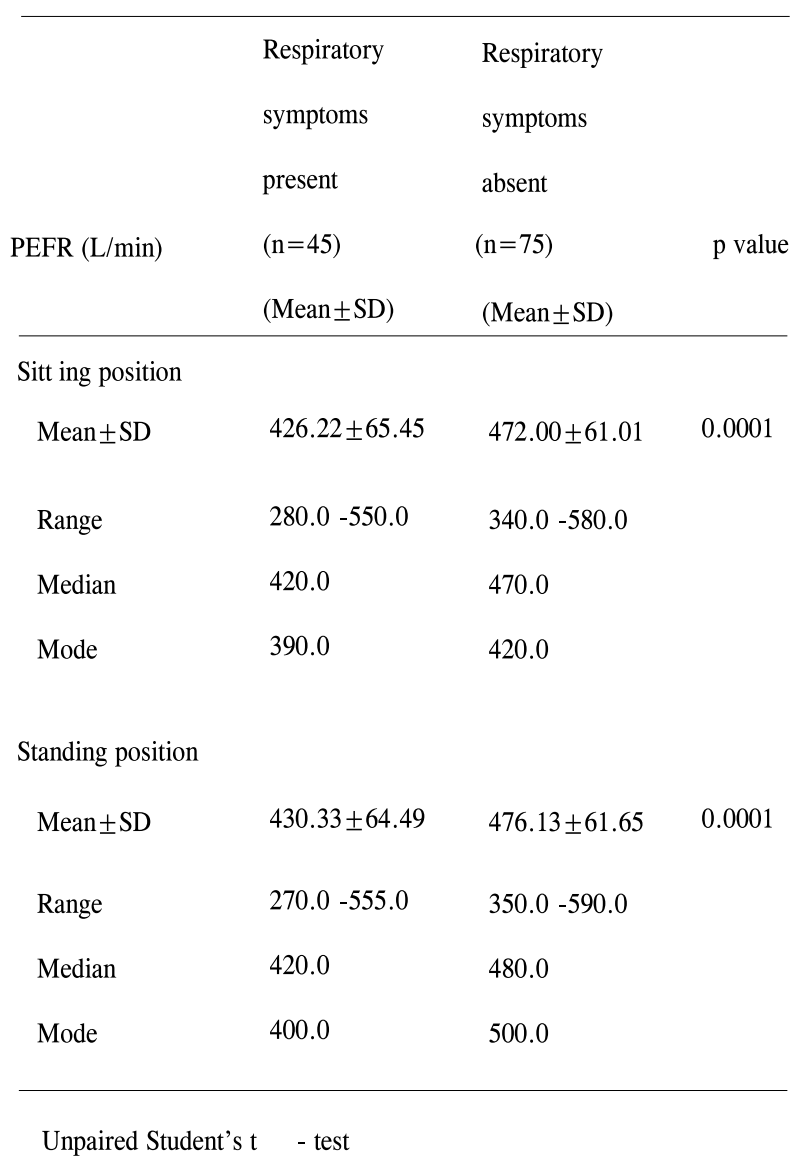

\section{Discussion}

This study was undertaken to find out some facts and figures regarding the respiratory problems affecting the goldsmith workers. Also some demographic data pertaining to the goldsmith workers were intended to be investigated. It was never an object of this study to diagnose respiratory ailments among the goldsmith workers since that would require more time, money, technical knowhow as well as manpower and effort which was not available to the researcher. Instead, to find out the magnitude of respiratory problems among the goldsmith workers the emphasis was on the history of the patient which was obtained through a questionnaire. To supplement this, physical examination was done as well as peak expiratory flow rate was ascertained. The motive behind taking PEFR was not to diagnosed to any disease, rather it was through that PEFR would be a good indicator of lung function. Since PEFR is reduced in obstructive lung diseases, Low value of PEFR may reflect latent or imminent obstructive lung disease like asthma, chronic 
bronchitis, emphysema - or at least impaired lung function. It was observed from the study that most of the workshops were very dusty, overcrowded and deviated of proper ventilation. In most cases, workers lived in this place in a crowded manner. So these were their working places as well as home where they lived.

This study identified that the working people of goldsmith workshops are male. This is a profession which female workers almost never taken up. Majority $(40.8 \%)$ of them are of age group (16-25years). No one of them found below 16 years. The average monthly income of the workers was Tk. 8608/=, majority $(31.7 \%)$ of the workers earn monthly within 7100-9000 Taka. The educational level of the studied workers differs from the workers of different industrial sector. The majority $(40.8 \%)$ of the studied workers were found with secondary level.

Regarding the length of service of the goldsmith workers the majority $(27.5 \%)$ of the respondents found who are working in goldsmith workshops for 16-20 years, a good number $(25.8 \%)$ served more than 20 years. It means that the turning over of employee from this occupation is very less, unless and until they become incapable of working. All the respondents reported during the study that they have to work in goldsmith workshop for more or less 8 hours a day with 1-2 hour interval. It depends upon the work load of the workshop. Generally the goldsmiths have weekend holyday on Friday.

From the study it was found that maximum number of respondents $(58.3 \%)$ were smokers. This correlates with the social trends in our country which is alarming. Of the smokers (88.5\%) smoked 6-10 sticks per day. The proportion of respiratory problems among the goldsmith workers is $45(37.5 \%)$. In this study it was found that symptoms of respiratory problems out of 45 respondents with respiratory problems running nose and / sneezing $(71.1 \%)$, cough (100\%), suffering from cough for 3 month or more in a year $(75.6 \%)$, phlegm $(66.7 \%)$, blood mixed phlegm $(18.9 \%)$.A study showed, long exposures to workplace gases and fumes were significant risk factor for pulmonary fitness amongst the goldsmiths of Indian unorganized sectors. Long exposure to those pollutants abruptly altered the lung functions of the workers. ${ }^{3}$

The findings of other authors reveal, the fumes of various metals, acids, and gases were associated with the deterioration of the pulmonary efficiencies of the goldsmiths.4 Sheel et al launched a term "dysanaptic," which they meant the disproportionate growth. They reported that restriction to the alveoli and parts of the upper respiratory tracts might be caused by disproportionate growth of the airways and the lung parenchyma and that dysanaptic growth could lead to the development of different types of lung diseases. ${ }^{5}$

Regarding the PEFR it was found that PEFR was significantly low $(\mathrm{p}<0.001)$ both in sitting and standing position, among respondents suffering from respiratory problems. Mean PEFR in sitting position was $426.22 \mathrm{~L} / \mathrm{min}$, and standing position 430.33 $\mathrm{L} / \mathrm{min}$ in respondents suffering from respiratory problems, and mean PEFR in sitting position 472.00 $\mathrm{L} / \mathrm{min}$, and standing position $476.13 \mathrm{~L} / \mathrm{min}$ in respondents not suffering from respiratory problems.

Chattopadhyay et al. showed that constant exposure to fumes and gaseous pollutants were associated with reduced forced vital capacity and peak expiratory flow rates, which could cause an alteration of respiratory health. The validity of assessment of PEFR over the other standard PFT (Pulmonary Function Test) indices lies in the context that the other indices (e.g. FEV1) are more sensitive in assessing bronchoconstriction of the airways while PEFR can be an effective measure for home monitoring of lung function. ${ }^{6}$

A study done among the weaving workers: assessment of lung function by peak flow meter. Study showed that the mean PEFR of the workers who were suffering from respiratory diseases was $406.75 \mathrm{~L} / \mathrm{min}$. and was significantly lower than that of the workers (509.30 L/min.) who had no respiratory diseases. ${ }^{7}$

In this study mean chest expansibility was $3.10 \pm 0.41 \mathrm{~cm}$. From another study it was found that PEFR was directly proportional to the chest expansion irrespective of sex and age but for the same age group and same chest expansion, PEFR differed by sex. So chest expansion is not only parameter controlling PEFR. ${ }^{8}$

\section{Conclusion}

This study comes to the conclusion with the realization of importance for occupational safety and health for the goldsmith workers who are at risk. Respondents were very much aware about the irritating dust hazards but many of them did not use personal protective equipments during the period of work. Pulmonary 
symptoms like running nose, sneezing, cough were more common among them due to exposure to coal dust, fumes of wax \& acid resulting significantly lower levels of lung functions. The occurrence of respiratory problems was found to be directly proportional to the length of service of the respondents and the occurrence of respiratory problems increased with the increased number of cigarettes smoked per day. Proper preventive measures should be taken and the affected cases should be given proper treatment facilities for the betterment of the labour force.

Conflict of interest: We have no conflict of interest.

\section{References}

1. Christoper H, Edwin R. Chilvers J, Hunter, Nicoolas A B. Davidson's principles and practice of Medicine, 18th ed, Harcourt Bracc and Company Ltd.; 24-28 Oval Road, London, NW 17 DX, UK:1999. P- 322-54, 370-74.

2. World Health Organization, Geneva, Switzerland, Early detection of Occupational diseases 1986 : P- 9-19.

3. Subhashis S, Biswajit R and Subhabrata M. Assessment of the lung function status of the goldsmiths working in an unorganized sector of India. Lung India, 2013, 30(1): 33-37.
4. Kelleher P, Pacheco K, Newman LS. Inorganic dust pneumonias: The metal-related parenchymal disorders. Environ Health Perspect. 2000;108(4): 685-96.

5. Sheel AW, Guenette JA, Yuan R, Holy L, Mayo JR, McWilliams AM, et al. Evidence for dysanapsis using computed tomographic imaging of the airways in older exsmokers. J Appl Physiol. 2009;107: 1622-1628.

6. Chattopadhyay BP, Alam J, Roychowdhury A. Pulmonary Function Abnormalities Associated with Exposure to Automobile Exhaust in a Diesel Bus Garage and Roads. Lung. 2003;181: 291-302.

7. Ahmad SK. A, Sarker A.M Sayed M.H S U.Weaving workers: Assessment of lung function by Peak Flow Meter. JOPSOM, 1997; 16(1): 37-43.

8. Badaruddin Md, Borhan Uddin Md, Khatun Firoza, Ahmed Khaled. Peak Expiratory Flow Rate and its Relation to Chest Expansion, Chest and Heart Bulletin; Jan 1993; 17 (1): 17-19. 